\title{
Reclamos da lavoura: A definição do programa de prioridades da indústria sacarina no
}

\author{
Primeiro Congresso Nacional de Agricultura.
}

\section{The demands of the Agriculture: The definition of a priority program for the sugar}

industry in the First National Congress of Agriculture

\section{Roberta Barros MEIRA*}

\begin{abstract}
Resumo: Este trabalho propõe-se a refletir sobre a influência da Sociedade Nacional da Agricultura na introdução de melhoramentos técnicos tanto na lavoura quanto nas usinas açucareiras, na Primeira República. Ao analisarmos as falas dos comícios rurais, das assembleias agrícolas e das exposições organizadas pela SNA ou das manifestações dos agricultores, técnicos e estadistas, nos diversos trabalhos publicados no período, percebemos que a Sociedade poderia ser definida como um centro disseminador das ideias de modernização agrícola, defendida pelos chamados "agricultores progressistas". Assim, deu-se ênfase às ideias levantadas durante o Primeiro Congresso Nacional da Agricultura. Neste sentido, procura-se mostrar a influência dos princípios do associativismo e qual seria o seu papel após a sua adequação à necessidade sentida pelos usineiros de modernizar a produção agrícola, arregimentar uma mão de obra livre no pós-abolição e barrar a ação dos especuladores. Ademais, indaga-se sobre as decisões dos chamados "agricultores progressistas" em renovar a lavoura por meio dos novos métodos de cultivo propagados pelos institutos agronômicos, fazendas-modelo, escolas práticas, dentre outros. Assim, o objetivo desta comunicação é relacionar as ideias defendidas pela SNA e pelos chamados "agricultores progressistas" no Primeiro Congresso Nacional de Agricultura e a atuação destes na "crise" da indústria sacarina no Brasil.
\end{abstract}

Palavras-chave: Sociedade Nacional de Agricultura, Primeira República, Indústria Sacarina.

Abstract: This paper proposes a reflection on the influence of the National Society of Agriculture in the implementation of technical improvements in the agriculture and in the modern sugar mills in the "Primeira República". In analyzing the speech of rural rallies, assemblies and agricultural exhibitions organized by the SNA or the manifestations of farmers, technicians and statesmen in the various studies published in the period, we see that the Society could be defined as a disseminator of ideas center of agricultural modernization, advocated by so-called "progressive farmers". Thus, emphasis was placed on the ideas raised during the First National Congress of Agriculture. In this sense, it attempts to show the influence of the principles of association and what their role would be after their suitability by the owners felt the need to modernize agricultural production, deploying a hand-free labor in

\footnotetext{
${ }^{*}$ Mestre em História - Doutoranda - Programa de Pós-graduação em História Econômica - Faculdade de Filosofia Letras e Ciências Humanas - USP - Departamento de História. Av. Prof. Luciano Gualberto, 315 CEP: 05508-900 - Cidade Universitária São Paulo - SP / Brasil. Bolsista Fapesp. E-mail:rbmeira@gmail.com
} 
the post-abolition and stop the action of speculators. Furthermore, we look into the decisions on the so-called "progressive farmers" to renew the plantation, through new methods of cultivation propagated by agronomic institutes, model farms, schools practices, among others. The objective of this communication is to relate the ideas advocated by the SNA and so-called "progressive farmers" and his role in "crisis" sugar industry in Brazil.

Keywords: Agriculture National Society, First Republic, Sugar Industry.

As crises dos preços no final do século XIX impuseram aos agricultores brasileiros a necessidade de discutir seus principais problemas e encontrar soluções. A elaboração de planos que contemplassem os interesses dos diversos setores agrícolas levaria à ampliação dos congressos e conferências como uma forma de organizar os representantes da lavoura, fossem eles do núcleo dominante, como os cafeicultores, ou dos setores secundários da agricultura brasileira. Como se sabe, um marco das discussões sobre os problemas da indústria açucareira no final do Império seria o Congresso Agrícola do Norte em 1878, organizado pela Sociedade Auxiliadora da Agricultura de Pernambuco ${ }^{1}$, como uma resposta ao Congresso Agrícola da Corte, que privilegiaria os cafeicultores.

Por outro lado, de todo decisiva foi a influência do Primeiro Congresso Nacional da Agricultura durante a Primeira República, por duas razões distintas. A primeira delas consistiu em deixar clara a importância que os produtores de açúcar outorgavam ao Estado, fosse na concessão de crédito, fosse na adoção do sistema de prêmios no País. A segunda foi o interesse de um grupo de agricultores pela defesa do associativismo, já com moldes um pouco distintos daquele que foi colocado em prática para os engenhos centrais. Ademais, há uma diferença substancial entre este Congresso em relação a seus predecessores, uma vez que nele se chegou ao ponto de definir as principais proposições de solução para a crise que a indústria açucareira enfrentava - não só para os anos da Primeira República, mas também para os anos seguintes marcados pela política do Instituto do Açúcar e do Álcool.

Seria impossível ignorar que a agricultura enfrentava uma crise agrícola, posto que esta não estava restrita ao Brasil. O agravamento da crise acabou por provocar a necessidade de maior intervenção por parte do Estado no último quartel do século XIX, de forma a contornar a Grande Depressão de 1870-90. O estímulo variou entre o protecionismo, o associativismo e a modernização agrícola. (Mendonça, 1990, p. 3) Assim, percebe-se que 
viria a haver reflexos imediatos sobre as decisões tomadas pelo Estado e pelos produtores de açúcar sobre as políticas europeias, tanto em relação à organização de inúmeros congressos agrícolas no período, quanto no que tange ao associativismo europeu, um dos principais movimentos gerados pela crise mundial dos preços agrícolas. Cabe ressaltar que o princípio da solidariedade foi considerado, em muitos países, a solução para organizar os interesses e enfrentamentos agrícolas. ${ }^{2}$ A consubstanciação dessas ideias com a realidade brasileira manteve inexorável o objetivo de agregar a dispersa e isolada população rural, mesmo que se pensasse aqui, principalmente, em termos dos grandes produtores. Assim, o associativismo seria incessantemente discutido nos congressos agrícolas como uma salvação para a "crise" da lavoura. Mas, conquanto as bases fossem as mesmas do movimento europeu, buscava-se adequar o associativismo à necessidade sentida pelos usineiros de modernizar suas fábricas e, sem dúvida, estimular maior controle da parte comercial - por sinal, a mais lucrativa.

Nos países cultos da Europa é isso uma verdade sem controvérsia, grandes esforços, muitas dedicações se têm empenhado para firmar e desenvolver a união dos agricultores sob a forma de sindicatos agrícolas e os efeitos, quer para o bem público, quer quanto à prosperidade, prestígio e força da lavoura. (SNA, 1907, p. 90)

Embora um grupo de usineiros se deleitasse em chamar o associativismo de a salvação para a maioria dos seus problemas econômicos, compreende-se que não seria fácil disputar com os comerciantes, chamados - dentre outros adjetivos - de "especuladores" e "parasitas" na disputa acirrada que se travou nesses anos. Assim, pode-se dizer que o associativismo vinha ao encontro, então, da necessidade de arregimentar os produtores em torno de cooperativas, associações e clubes agrícolas que possibilitassem a comercialização dos produtos pelos próprios produtores, eliminando a figura do intermediador, como podemos perceber na fala de Emmanuel Couret, representante dos usineiros campistas.

Com o desenvolvimento das culturas e concorrência internacional reduziu-se a margem de lucros nos preços de venda dos produtos; ele, porém, continuou a manter a mesma forma de comércio intermediário, o qual, por instinto de conservação, multiplicou seus artifícios de ganho que insensivelmente degeneraram no mais esgotante parasitismo da lavoura. (SNA, 1907,p. 60) 
Naturalmente, os baixos preços e as oscilações constantes contribuíram em muito para esta postura. Durante todo o período da Primeira República, várias tentativas de formar associações que limitassem o poder dos especuladores foram feitas pelos produtores do Rio de Janeiro e do Nordeste do País, sem resultados satisfatórios. Não cabe aqui discutir as razões que levaram a este quadro, mas apontar as tentativas de organização criadas em torno de interesses comuns, posto que os próprios agricultores enfatizavam o isolamento dos fazendeiros e a dificuldade de organizá-los. Pesam, ademais, as diferenças regionais, se considerarmos que o Nordeste, com a perda do mercado externo, transformou-se no fornecedor da região Sudeste.

\begin{abstract}
Acrescenta-se a esta preocupação, a crise de preços enfrentada pela agricultura brasileira, que também atingiria o seu principal produto na pauta de exportações. Os meios práticos e urgentes de atenuar a crise da lavoura de cana são a supressão dos intermediários entre a produção e o consumo pela instituição de sindicatos agrícolas com direitos e responsabilidades solidários, fazendo eles o papel de prestamistas a longos prazos e moderados juros para com seus associados; a emissão de letras hipotecárias, warrants, etc. (SNA, 1907)
\end{abstract}

Certamente, não seria excessivo afirmar que a Sociedade Nacional da Agricultura seria a principal patronesse do associativismo no Brasil durante a Primeira República. Como diria Wencesláo Bello, um dos seus primeiros presidentes, "a sociedade despertou a consciência da agricultura como classe. Dantes era ela a disseminação egoística ou o ajuntamento acidental efêmero; hoje, sugestionada pela afinidade dos interesses coletivos, propende acentuadamente para a associação e para o cooperativismo definitivo”. (A lavoura, 1908, p.6). Ademais, pode-se constatar tal aproximação com estas ideias pela própria escolha do lema da Sociedade: "viribus unitis" - o mesmo utilizado pelos representantes do associativismo francês. 


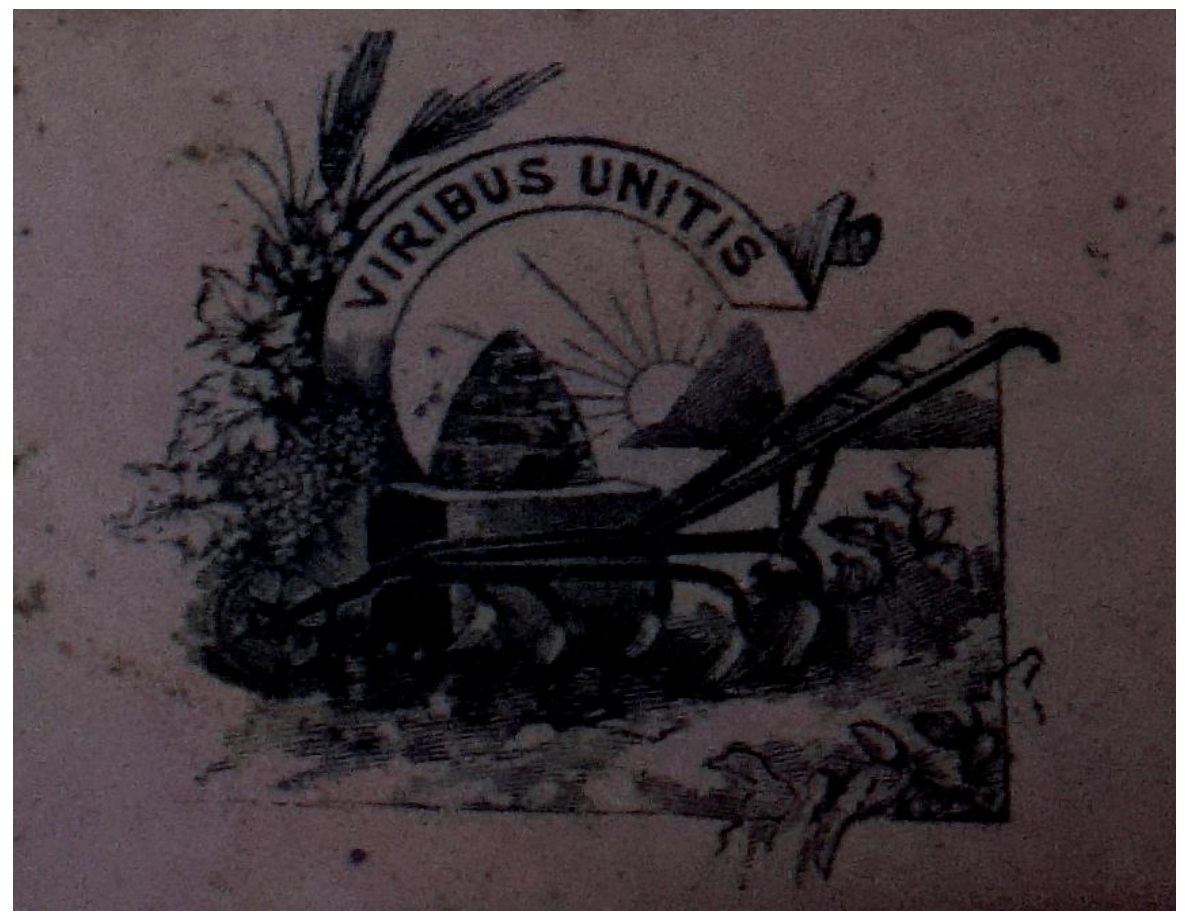

Fonte: SNA. Legislação Agrícola do Brasil. Rio de Janeiro: Imprensa Nacional, 1911.

Parece claro o motivo que teria forçado a criação da SNA. A extinção do Ministério da Agricultura, Comércio e Obras Públicas logo nos primeiros anos da República, subjugando os problemas agrícolas ao sobrecarregado Ministério da Indústria, Viação e Obras Públicas, conseguiu congregar, em 16 de janeiro de 1897, uma fração dos setores agrícolas não vinculados ao complexo cafeeiro mais dinâmico do País, embora não deixassem de pertencer à elite econômica brasileira. ${ }^{3}$ Nos seus estatutos, a Sociedade já buscava aclarar que era formada pela associação de lavradores e amigos da agricultura contrários à hegemonia da política cafeeira e que tinham como objetivo "empenhar coletivos e individuais esforços em bem da agricultura, ocupando-se de todos os assuntos que possam trazer o progresso da República dos Estados Unidos do Brasil’.' (Mendonça, 1997)

Não obstante seus membros pertencerem a grupos agrários diversos, como pecuaristas e usineiros, seriam extremamente compatíveis quando a pauta de discursões girava em torno de questões como a necessidade da modernização agrícola do País. Nesse sentido, não se deve estranhar que a Sociedade Nacional da Agricultura seja definida como um centro disseminador das ideias de modernização agrícola, defendida por homens que se distinguiam pelo epíteto de "agricultores progressistas" ou se autoproclamavam os responsáveis pelo "revivamento agrícola" do Brasil. Com esse intuito, a Sociedade se responsabilizaria pela 
promoção de associações rurais, cooperativas e caixas de crédito, fundação de campos de demonstração, escolas práticas de agricultura, aperfeiçoamento dos trabalhos agrícolas mediante maior aplicação das novas técnicas científicas ao campo, dentre outras funções.

Neste quadro, não se pode deixar de aludir à importância da SNA como um dos atores do processo de articulação entre agricultura e Estado. São extremamente numerosos os relatos sobre a importância da atuação da Sociedade como canalizador dos produtores rurais até 1906, devido, em grande parte, à falta de um órgão específico para atender às demandas dos setores não cafeeiros. Tal fato foi apontado pelo Ministro do Estado dos Negócios da Indústria, Viação e Obras Públicas, Lauro Severino Müller, nesse mesmo ano:

Por este Ministério foi confiada à Sociedade Nacional da Agricultura a direção da distribuição de plantas e sementes, a propaganda das aplicações industriais do álcool, conforme o dispositivo orçamentário, além dos serviços que ela presta dedicadamente ao Governo nas consultas que lhe são dirigidas em assuntos de agricultura e sobre a restituição de despesas com a importação de reprodutores de raças. (Brasil, 1906, p. 3-4)

Durante toda a importante trajetória da SNA, cujos frutos chegaram até mesmo a propiciar a recriação do Ministério da Agricultura em 1909, é basicamente impossível ignorar o plano de ação para o reerguimento da agricultura nacional elaborado durante o Primeiro Congresso Nacional da Agricultura. Mesmos com alguns percalços, a SNA conseguiu enfim efetuar o Congresso em 20 de setembro de 1901. Talvez o alto significado das suas proposições estivesse ligado ao fato de ter suas bases projetadas sobre a crise mundial que, como não poderia deixar de ser, afetou a agricultura do País no ano de 1901, mas também pela conjuntura anterior do Império e os apontamentos já levantados no Congresso Agrícola de 1878, e que foram estrategicamente apropriados por estes homens. Nesse caso, deve-se notar que o intuito dos organizadores do Congresso era estudar as "necessidades mais urgentes da lavoura e os meios mais eficazes de minorar a crise atual”, sendo discutidos os seguintes pontos: situação atual e necessidades da lavoura de café, cana de açúcar e das indústrias de criação e laticínios; meios práticos e urgentes de atenuar a crise desses ramos de produção; determinação das medidas que cabem ao lavrador e aos poderes públicos na solução da crise; união e crédito agrícola - meios de organizá-los; comércio e propaganda do café e do açúcar brasileiro. (SNA, 1907) 
Releva notar que estas questões teriam importância até nos embates pós-30. Para Miguel Calmon Du Pin e Almeida (1913), que foi um ativo colaborador da Associação, os pontos mais importantes defendidos pela SNA foram: o fim dos impostos interestaduais, a defesa da formação de sindicatos agrícolas e cooperativas, a propaganda do álcool, a criação do Ministério da Agricultura e a policultura. A ideia do Congresso surgiu em sessão de diretoria da SNA, em 20 de junho de 1899, e seu regulamento apontava que:

O Congresso terá por fim o estudo das questões que mais interessam à agricultura nacional, discutindo e resolvendo sobre o modo prático porque os agricultores e os poderes públicos devem cooperar com a prosperidade de nossa indústria agrícola. (SNA, 1907, p. 4)

O congresso foi dividido em 10 secções. Nesse sentido, por uma questão de impossibilidade de tratar em tão pouco tempo tal gama de produtos, essa análise passa ao largo das linhas estratégicas desenvolvidas para sanar os males da agricultura nacional como um todo. Assim sendo, o presente trabalho restringiu-se à segunda secção - Lavoura, Comércio e Propaganda do Açúcar e seus Produtos -, principalmente no que tange à questão dos mercados interno e externo e às conclusões sobre a melhor forma de estimular a produção açucareira, seja a partir da modernização do setor, concessão de prêmios de exportação, dentre outros meios. Ou seja, a proposta se restringiu a discutir as medidas sugeridas e, sobretudo, as preocupações dos diversos atores envolvidos, fossem eles representantes da indústria sacarina tanto do Norte quanto do Sul.

Como já se viu, é de notar a permanência das questões apontadas no Congresso de 1878 , isto é, meio circulante ou dinheiro; vias de comunicação; instrução profissional, prática e superior; diminuição do imposto de exportação sobre os produtos agrícolas e a sua substituição pelo imposto territorial; desamortização imediata das grandes propriedades do Estado; discriminação das matérias tributáveis pelo poder geral, provincial ou municipalidades. (SAAP, 1979) Embora o Império não deixasse de contar com observadores atentos dos principais problemas que obstavam o desempenho da lavoura nacional, estes homens não tiveram tanto sucesso em aplicar rapidamente as soluções necessárias. Além do mais, a superação da desvantagem técnica dos senhores de engenho brasileiros frente a seus concorrentes, fossem eles produtores de açúcar de beterraba ou de cana, não seria tão facilmente solucionada. Isto se figurou nítido com a construção dos engenhos centrais, vistos quase como os redentores da indústria açucareira brasileira. Seja como for, sua meio 
malograda experiência demonstra que nem sempre basta querer para chegar ao fim que se deseja.

Além do mais, não se pode deixar de relacionar as questões mais discutidas pelos congressistas com um fato específico: a perda do mercado externo e a necessidade de reorganização da produção, que se tornava quase que restrita ao consumo do próprio País. Nada mais salutar para percebermos a perda nos mercados consumidores do que a fala de um dos congressistas: "mercados novos ou não se criam, ou se limitam a importações diminutas". O açúcar brasileiro sofria cada vez mais a concorrência dos novos países produtores, como Cuba, Porto Rico e Filipinas, além da ameaça de fechamento do mercado americano para o açúcar brasileiro. O representante dos produtores de Campos, Mannuel Couret, chamou a atenção para esse problema e citou na sua exposição trechos da Memória do Ministério da Agricultura dos EUA.

Quase todas as importações tropicais em breve se produziram em Cuba, Porto Rico, Filipinas e Havaí, dado não só as aptidões produtivas destas ilhas, como do capital de que dispomos e as iniciativas, procedentes dos instrumentos da nossa indústria. Além do tabaco e do açúcar que já produzimos e que essas ilhas darão em grande quantidade, poderemos ali obter cacau (...) (SNA, 1907)

Pelo que se vê nos discursos, permanecia a ideia defendida no final do Império de que o único meio de recuperar parte do mercado externo era a introdução das inovações técnicas, tanto na lavoura quanto na indústria. Esse seria um dos meios de produzir um açúcar mais barato, competitivo e de melhor qualidade. No entanto, nem todos pensavam desta maneira. Uma voz dissonante acirrou o debate na Secção. Francisco de Paula Leite e Oiticica ${ }^{4}$ questionava a defesa que tais avanços técnicos trariam para a indústria sacarina, uma vez que mais compensava, economicamente, preparar um açúcar de pior qualidade.

O bom açúcar produz proporcionalmente menos que o mau, e falo com estabelecimento de causa, pois sou produtor de açúcar. Os donos de usinas foram obrigados a modificar o fabrico de açúcar de boa qualidade para o do açúcar pior a fim de se poder fazer a exportação; abandonaram o processo de purgar o açúcar, porque o açúcar branco fica mais caro e é vendido por menos, relativamente, que o açúcar bruto. E isto pode ser atestado por todos os fabricantes. O açúcar purificado é vendido por mais cem ou duzentas arrobas do que o açúcar bruto, tendo, entretanto, o seu fabrico custeado muito mais do que o deste. (SNA, 1907, p. 151) 
Ademais, aponta que, quando esse açúcar era exportado, o bom e o mau açúcar eram misturados e enviados como um tipo único para os mercados estrangeiros. Sendo assim, o produtor não poderia aceitar o conselho de fabricar um bom açúcar "que não acha um preço compensador da despesa feita." (SNA, 1907, p. 152)

Ora, apesar dos vários apartes contrários e a favor, o congresso seguiria a convicção da maioria dos congressistas e definiria como uma das suas conclusões aconselhar aos fabricantes de açúcar "a introdução dos melhoramentos necessários em suas fábricas e o máximo cuidado na fabricação”. (SNA, 1907, p. 152) Na visão de Estácio Coimbra ${ }^{5}$, outro representante do Norte, não era intuito do parecer afirmar que essa seria a solução para a crise do açúcar, já que essas eram noções gerais de agricultura, que já deveriam ser conhecidas e praticadas por todos 6 .

Tal necessidade certamente implicaria na questão do crédito agrícola. Não havia como a lavoura efetivar esses novos maquinismos com os preços baixos do produto e sem auxílio do Governo. Como apontava Américo Werneck, "todos esses conselhos seriam muito vantajosos se, com eles, fosse fornecido o capital. Os lavradores de cana estão em péssimas condições, piores que a dos lavradores de café”. (SNA, 1907, p. 152) Ademais, os produtores reclamavam dos impostos, principalmente dos interprovinciais, vistos como anticonstitucionais. $^{7}$

Considerando que, em virtude do citado art. $35 \S 2$ da Constituição, a União e os Estados devem cooperar com os agricultores na fundação do crédito agrícola, não só pela isenção de impostos e concessão de outros favores, como também pela garantia de juros. (SNA, 1907)

Neste quadro, o aumento da produção, a especulação e a falta de mercados estavam rebaixando os preços do açúcar a tal ponto que muitas vezes não se conseguiam pagar os custos da produção. Decorre dessa reclamação hegemônica a posição favorável ao associativismo. Esse ponto foi extremamente defendido pelo representante de Campos, Mannuel Couret. Segundo ele, o papel muitas vezes negativo dos comissários e a falta de união dos produtores explicavam em grande parte a baixa dos preços no mercado do Rio de Janeiro.

No Rio de Janeiro há quatro compradores de açúcar, vendendo-se, entretanto, setenta e cinco mil sacas de açúcar mensalmente: estes quatro 
compradores, com o capital, com a força, enfrentando-se com quem está desarmado, impõe diariamente o preço. Assim, chegamos a atual situação: o preço de venda do açúcar não cobre o do custo. (SNA, 1907, p. 267)

A solução defendida passava pela união dos lavradores. Para Couret, o lavrador precisava organizar sua casa vendedora, incorporando os comerciantes ou não, mas as negociações deveriam ser diversas das que eram feitas, pois os comissários não conseguiam atender às necessidades dos produtores, pois chegavam a pagar 240 réis pelo açúcar e vendêlo a 500 réis. Assim, "é preciso que os lavradores se reúnam em sindicatos que exerçam sua ação nos grandes centros de permuta." (SNA, 1907, p. 103)

Mas, em geral, o tema que mais prendeu a atenção dos congressistas foi os prêmios de exportação. Segundo a defesa, essa seria a única forma de competir com o açúcar de beterraba europeu, já favorecido pelos mesmos prêmios: aumentar o preço do açúcar no mercado interno, com a diminuição dos estoques; possibilitar ao produtor os incentivos para modernizar a lavoura e a fábrica; criar escolas agrícolas, bancos rurais; etc. O capital necessário para os prêmios seria levantado por meio de um imposto de consumo e repassado para os lavradores que exportassem parte da sua produção.

Eles levantarão, entre nós, a lavoura de cana, como fizeram evoluir na Europa a da beterraba. Os prêmios de produção concorrem eficazmente para o crescimento da riqueza sacarina da beterraba, mormente na Alemanha, onde se verifica a riqueza em açúcar de $15 \%$ do peso da raiz, chegando até $17 \%$ como assegura Grandeau. Graças a essa providência, que quisera ver praticada no Brasil, a produção de açúcar naquele país, quer pela pratica da cultura, quer pelo processo, da difusão, ter excedido a de todos os países produtores, seguindo-se lhe em escala descendente a Áustria e a França, onde o sistema dos prêmios é aplicado desde meados do século XVII, conforme assinala Yves Guyot. Em consequência desse sistema e de outras medidas complementares, o açúcar de beterraba vem competir vitoriosamente com o açúcar de cana brasileiro em o nosso continente, como se observa no mercado de Montevidéu. (SNA, 1907, p. 165)

Um dos principais opositores, Estácio Coimbra, defendia que se o País adotasse tal medida perderia os mercados dos Estados Unidos e da Inglaterra. O congressista não negava que os prêmios seriam um estímulo, mas ficariam anulados se os países consumidores adotassem os impostos compensatórios. Segundo ele, se o Brasil assinasse tratados de comércio, reduzisse as tarifas das estradas de ferro e diminuísse os fretes marítimos chegaria à 
solução da crise do açúcar "sem haver necessidade de prêmios, de proteção direta". (SNA, 1907, p. 158)

Se observarmos especificamente o setor açucareiro, constatamos que a crise era mundial. Como se sabe, numa tentativa de sanar esse problema, em 1901, foi organizada pela Inglaterra $^{8}$ a Conferência de Bruxelas. A partir desse momento, foi acordado que os países signatários se comprometeriam a eliminar as subvenções, limitar as tarifas protecionistas e a preferência pelos produtos coloniais, além de ampliar as restrições contra os açúcares subvencionados. Essa defesa seria explicitada no artigo $4^{\circ}$ do Acordo:

As altas partes contratantes obrigam-se a taxar com um imposto especial à importação, em seus respectivos territórios dos açúcares provenientes de países que concederem prêmios, à produção ou à exportação. Este direito não poderá ser inferior à soma dos prêmios diretos ou indiretos, concedidos no país de origem. As altas partes se reservam a faculdade, cada uma no que lhe diz respeito, de proibir a importação de açúcares premiados". (Rio de Janeiro, 1902, p. 72)

Mas, como quer que seja, as divergências dentro do próprio setor açucareiro influenciaram o Brasil a não assinar o Acordo nesse momento. Destaca-se, nesse caso, a defesa favorável da Sociedade Auxiliadora da Agricultura de Pernambuco. Essa Sociedade afirmava que esse seria o único meio de reconquistar os mercados europeus. Além do que, a redução das tarifas protecionistas levaria a indústria açucareira nacional a melhorar sua eficiência. Evidentemente, os representantes ingleses da indústria açucareira também eram favoráveis à adesão. Tal posição seria defendida na The Brazilian Review. ${ }^{9}$ É contundente, nesse caso, o apoio dado por Frederic Sawyer. Segundo esse autor:

A adesão do Brasil a Convenção de Bruxelas se há de impor, provavelmente pelas circunstâncias, com a conseqüente redução de direitos de alfândega sobre o açúcar estrangeiro. Se tal fosse a causa do fechamento de todas essas usinas atrasadas e dispendiosas, seria também o princípio de uma nova era de prosperidade para a indústria açucareira do Brasil. Os campos produziriam o duplo de açúcar, sendo o de melhor qualidade a preços econômicos capazes de lutar com quem quer que seja, os jornais se elevariam permitindo ao proletariado viver com decência, e se evitaria a funesta devastação dos matos que pouco a pouco vai reduzindo a precipitação de chuvas nos estados açucareiros. (Sawyer, 1905, p.11)

Apesar da formação de duas correntes - de um lado, os contrários à decretação dos prêmios, e do outro, os que se declaravam favoráveis à ideia -, os prêmios de exportação não 
foram adotados pelo país, apesar de o Brasil só passar a ser signatário do Acordo de Bruxelas em 1906. Sem colher, no entanto, os resultados esperados, acabaria por se retirar do Convênio. ${ }^{10}$

Por tudo isso, seria de esperar que a maioria dessas medidas fosse posta em prática, visto que muitas dessas ideias já eram levantadas desde o período do Império. No entanto, a indústria sacarina passava por uma conjuntura bastante negativa, ocasionando um lento processo de mudanças. Isto não significou, todavia, a inexistência de melhorias e de crescimento durante a Primeira República. Nesse quadro, o Primeiro Congresso Nacional de Agricultura destacou-se por conseguir reunir os diversos atores e levantar os principais problemas da produção açucareira. Apesar das delongas, muitas dessas ideias foram colocadas em prática anos depois, com a criação do Instituto do Açúcar e do Álcool, que resgatou e implantou várias das soluções propostas em 1901. Enfim, a política de estímulo às usinas tomou forma a partir do momento em que os produtores passaram a discutir seus problemas e reafirmaram o papel fundamental das associações para a recuperação da indústria sacarina.

Ademais, ao considerarmos o processo de diversificação almejado pela SNA, contrária à monocultura do café, percebe-se a influência direta dos representantes da indústria açucareira, posto que levavam em conta a necessidade de arregimentar um maior auxílio estatal para a sua recuperação. A sua atuação consubstancia-se com as próprias vitórias da SNA, já que dos 11 ministros do Ministério da Agricultura Indústria e Comércio, entre 19091930, três eram usineiros, e todos eles eram membros da Sociedade - tendo sido Miguel Calmon Du Pin e Almeida um dos seus presidentes.

Segundo o próprio Miguel Calmon, a situação da indústria açucareira em 1901 era de completa ruína", "sendo que talvez a produção não pudesse manter-se, sequer, para o mercado interno". Para ele, foi possível uma reação calcada nos princípios da solidariedade depois do Primeiro Congresso Nacional da Agricultura. Outrossim, a partir da realização frequente de congressos que discutiam a produção açucareira, irradiaram-se ideias de união dos produtores contra a ação dos comerciantes "especuladores", a defesa de políticas agrícolas, de criação de bancos de crédito regionais e a necessidade de melhorar as técnicas de produção tanto da lavoura quanto da fábrica.

A reação dos produtores de açúcar brasileiros tinha vinculação direta com a conjuntura internacional. Um exemplo seria a celeridade do desenvolvimento da indústria açucareira em vários países, antes importadores de açúcar, que passaram progressivamente da 
autossuficiência para a exportação, muitas vezes até com concessão de prêmios, como no caso da Argentina. Some-se o grande incremento da produção de açúcar de beterraba, impulsionado pelo aperfeiçoamento contínuo das usinas de açúcar europeias, e teremos a formação de uma crise de superprodução mundial.

Nota-se que o açúcar brasileiro não era o único a sofrer com a oscilação e baixa nos preços no comércio mundial. Em um período de inovações de uma rapidez ainda desconhecida nos anos anteriores, os produtores de açúcar do Brasil poderiam alegar que estavam defasados tecnologicamente, tanto quando comparados aos países produtores do açúcar de beterraba como em relação aos grandes fornecedores de açúcar de cana, como Cuba. Ao analisarmos o gráfico 1, temos uma nítida ideia do aumento da produção do açúcar de beterraba e do açúcar de cana. Chega-se, aqui, à questão que perturbava ao extremo os produtores de açúcar brasileiros - sua incapacidade de ombrear com esses países, fosse em relação à quantidade de açúcar produzido, à qualidade da produção e, principalmente, à tecnologia produtiva em uso pelos seus rivais.

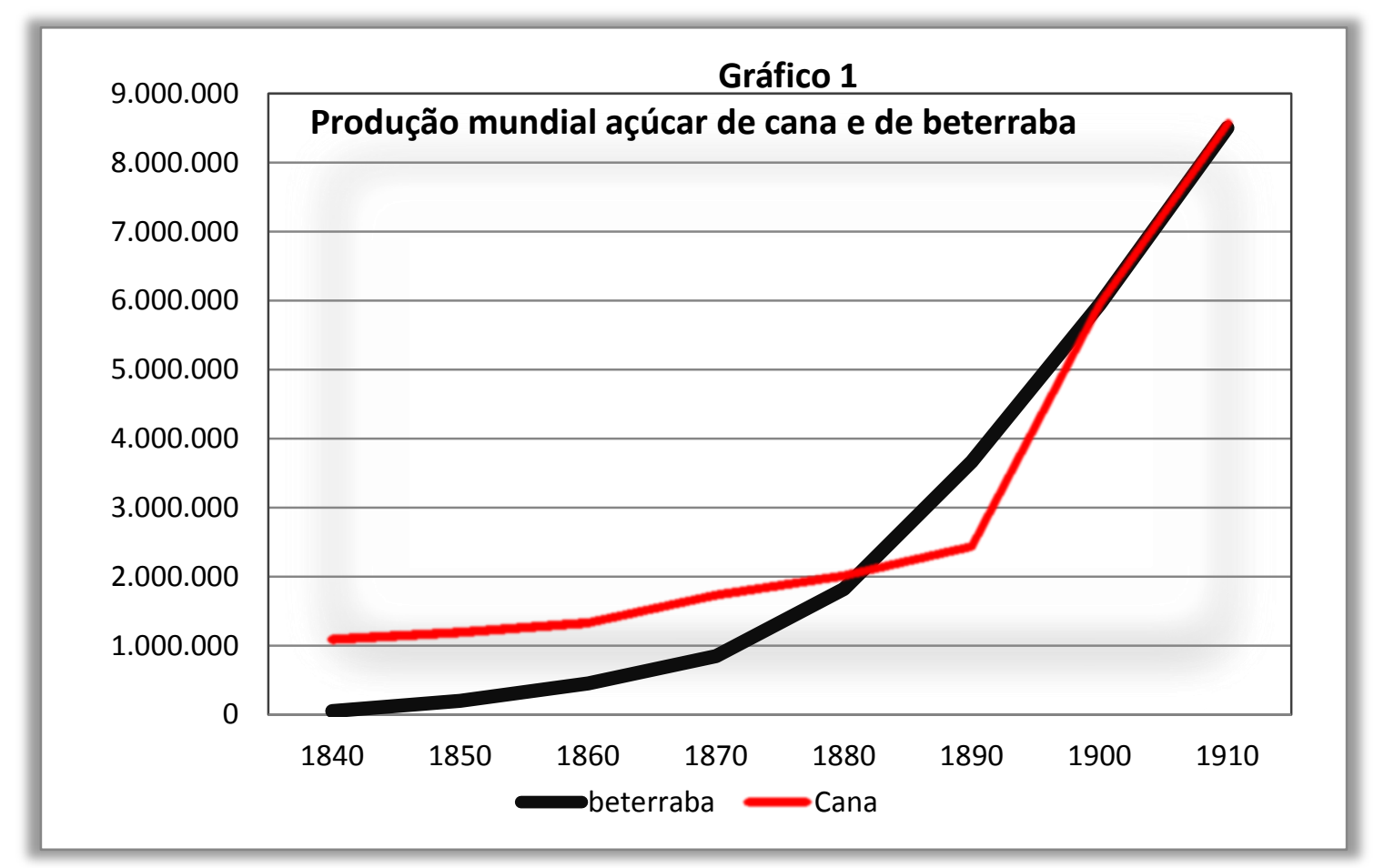

Fonte: MAIC. Boletim do Ministério da Agricultura, Indústria e Comércio. Rio de Janeiro: Tipografia do serviço de Estatística, janeiro de 1913. 
Nem na Europa nem nos Estados Unidos, os produtores de açúcar brasileiros encontravam um mercado seguro. Esta questão, levantada frequentemente por homens que se ligavam diretamente à indústria sacarina, apontava que ou o País recuperava o mercado externo ou se restringia ao interno. É preciso que se tenha em conta que o traço marcante da Primeira República foi apresentar índices que mostravam que o açúcar produzido era quase todo consumido no Brasil, sendo exportado apenas o excesso, uma vez que não seria razoável esperar que o consumo interno absorvesse toda a produção. Ademais, nunca foi uma alternativa levantada pelos produtores de açúcar perder o mercado externo. Ao mesmo tempo que se estabelecia uma luta cada vez mais acirrada pelo consumidor nacional entre os estados produtores tentavam-se restabelecer os pressupostos da ordem vigente dos áureos tempos do açúcar brasileiro, ou seja, a retomada do mercado externo faria cintilar ainda por um bom tempo os olhos dos produtores nacionais, ainda mais se se lembrasse que a exportação de açúcar durante a Primeira República foi impulsionada por um curto período pela destruição dos campos de beterraba por causa da Primeira Guerra Mundial, como se nota no gráfico 2.

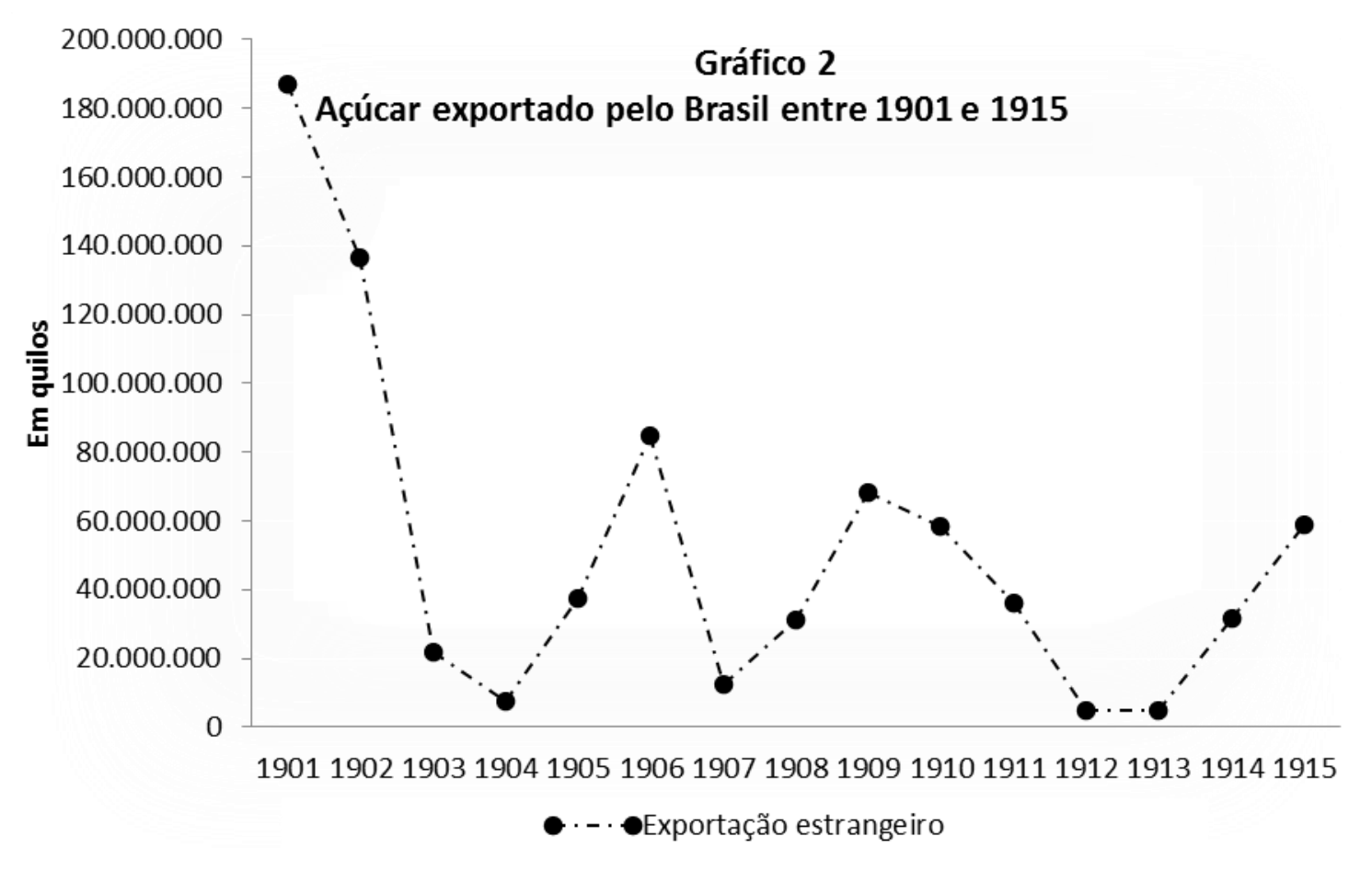

Fonte: A Lavoura. Boletim da Sociedade Nacional da Agricultura. Rio de Janeiro: Imprensa Nacional, janeiro a junho de 1916. 
A percepção de que só a adoção dos avanços técnicos, tanto na parte fabril como na lavoura, poderia conduzir o Brasil ao mesmo estágio de países como Cuba e França se fez presente em quase todas as falas dos congressistas no primeiro Congresso Nacional de Agricultura e nos que se seguiram. Caberia dar-se toda a atenção à fala de Paulo de Amorim Salgado $^{12}$, principalmente pela sua atuação constante na organização de congressos e conferências que debatessem a questão açucareira. Uma análise da sua apresentação no Primeiro Congresso Nacional da Agricultura, denominada "monografia sobre o aperfeiçoamento da cultura da cana de açúcar tendo em vista a sua riqueza sacarina”, aponta para uma preocupação maior com a cultura da cana. Em um período em que as inovações técnicas introduzidas ainda se concentravam na parte fabril, a sua fala inclinou-se acentuadamente para as melhorias na lavoura.

A ideia esposada por Paulo de Amorim Salgado ia de encontro à própria oposição, gerada pela defesa de que os métodos de cultivo anteriores eram atrasados. Criava-se uma oposição entre a chamada "lavoura vampira" em detrimento de uma nova agricultura, racional e moderna. Para ele, as vicissitudes da lavoura, os problemas com a mão de obra provocados pelo abolicionismo, as moléstias da cana-de-açúcar e o insucesso dos engenhos centrais levaram o agricultor a "continuar no empirismo dos velhos processos culturais há muito condenados pelos princípios científicos".

Estas sugestões constituem peças descritivas da mentalidade do período. A solução, neste caso, estava em renovar a lavoura e tirar o agricultor da rotina. Para isto, uma atuação mais ativa do estado era reclamada. ${ }^{13}$ Um dos problemas do País, para ele, seria a falta de institutos agrícolas e estações agronômicas que abundavam nas colônias inglesas e francesas e nos Estados Unidos, fundamentais para o melhoramento das canas e fim das pragas.

Ocorre que a indústria açucareira no Brasil, despojada por muito tempo de melhoramentos no cultivo da cana, veria o sucesso dos avanços na extração e qualidade da sacarose da beterraba e as pesquisas do melhoramento nas variedades da cana-de-açúcar nas colônias espanholas, inglesas e francesas como uma amostra da desvantagem do açúcar brasileiro. Alternativa não teriam, senão adotar a mesma postura destes países concorrentes, e para isto cobravam do Governo a criação de institutos agronômicas, fazendas-modelo, escolas práticas, etc. Esta concepção que formularia as futuras demandas políticas dos produtores de açúcar após o Congresso de 1901 fica patente já na fala de Salgado. 
Os países inter-trópicos precisam, para salvarem-se, que a cana, imitando o que se deu com a beterraba, aumente até duplicá-la, a proporção da sacarose, que ainda hoje é a mesma apresentada há uns 200 ou 300 anos; para conseguir este resultado, os processos culturais tão importantes e a natureza não nos oferecem outro meio senão a reprodução sexual, isto é, por meio de sementes fecundadas, da própria cana, que, em virtude da lei de hereditariedade e da variação, produziram variedades, às quais aplicar-se-á a seleção. Desconhecida até bem pouco tempo, a possibilidade de obter das minúsculas sementes de flecha a reprodução da cana não é mais sujeita a dúvidas, e nesta metade última do século XIX, as ilhas Barbados, Guadalupe e Martinica têm presenciado tentames deste gênero seguidos o mais favorável êxito. (SNA, 1907)

Convém observar que os diversos autores que trataram da questão apontam que nos métodos de plantio não se observavam os princípios agronômicos modernos, como: arar o terreno, respeitar o espaçamento adequado entre as fileiras da cana, obedecer à época certa para o corte, a necessidade de irrigação ou drenagem, dependendo do terreno e da região, a utilização de adubos nas terras já cansadas, etc. Assim, ao mesmo tempo que se estabeleciam os pressupostos da moderna agricultura no Brasil buscava-se propagá-la entre os agricultores ainda presos aos velhos métodos de cultivo e à "rotina". Nesse sentido, o Congresso Agrícola de 1901 recomendava: escolha da variedade da cana a plantar; seleção da semente para o plantio, estrumação, irrigação dos canaviais; e que as fábricas de açúcar não deveriam mais comprar essa matéria-prima por peso bruto, senão pelo peso em açúcar.

Usava-se à exaustão a defesa dos avanços científicos como forma de produzir mais e diminuir os custos da produção. É preciso, contudo, não levar em consideração apenas a necessidade dos produtores de açúcar em exportar o excesso da produção ou recuperar parte do mercado externo, mas a própria ideologia do "progresso". A agricultura passaria, aos poucos, ao domínio dos "homens da ciência", isto é, químicos, agrônomos, engenheiros e os chamados "agricultores progressistas". Nada é mais ilustrativo do que a constante menção à disparidade entre a agricultura brasileira e a estrangeira.

Nos países onde a agricultura é bastante adiantada pelo benéfico influxo da ciência que, derruindo velhos preconceitos, fez desaparecer condenados processos que a rotina teima em conservar; nos países onde a cultura da terra é feita de acordo com as lições da ciência e subordina-se as regras e ditames da economia rural, o objetivo principal do agricultor, é produzir muito e 
bem, com o menor emprego de capitais, em menor lapso de tempo e com menos trabalho possível, ou por outra, produzir muito barato. (SNA, 1907)

Ocorre que as reações nacionais de restauração da indústria sacarina são plausíveis, se pensarmos que toda uma região do País dependia deste produto, além de ele ser representativo em outras regiões, como Campos, no Rio de janeiro. Esta reação que parte dos próprios agricultores busca a superação de uma crise que ameaçava aniquilar o setor, reduzi-lo ao mercado interno, o que seria inadmissível para estes produtores. A superioridade das terras, da riqueza sacarina da cana-de-açúcar, o clima, proclamados sempre como a maior vantagem do açúcar brasileiro, vinham ao encontro da defesa dos investimentos neste setor, pelo Estado ou pelos próprios agricultores, como aponta Emmanuel Couret, representante da lavoura de Campos.

Eu creio absolutamente no futuro da lavoura de cana no Brasil e estou convencido que no dia em que ela for praticada com os conhecimentos científicos; no dia em que o fabrico se der com as máquinas que existem mais aperfeiçoadas, o açúcar de cana no Brasil irá ocorrer com vantagens nos mercados dos países da Europa que procurem esse artigo, cuja indústria é sustentada por prêmios e favores governamentais. Para chegarmos a esse fim é preciso não só acudir de pronto à nossa lavoura que agoniza como conhecer-lhe os meios de gradual, mas seguramente operar as transformações precisas.(SNA, 1907)

Contrastando com a situação precedente, de parcos e pontuais avanços técnicos feitos por alguns fazendeiros mais abastados e inovadores, o período entre o final do Império e a Primeira República seria um marco na agricultura brasileira. A percepção de que só o aprimoramento dos métodos de cultivo e a melhoria do maquinário nas fábricas poderiam reerguer a agricultura brasileira e a indústria sacarina levou ao desenvolvimento de todo um plano de ação dos chamados "agricultores progressistas". Se houve uma excessiva atenção ao I Congresso Nacional da Agricultura foi por ele indicar perfeitamente o espírito que representou um grande ascendente sobre os produtores de açúcar durante a Primeira República: a necessidade de modernizar a produção para se adaptar à realidade mundial. E mais ainda, foi neste Congresso que um grupo de homens viajados e instruídos formulou as diretrizes das medidas salvacionistas da indústria sacarina brasileira por um largo período. Algumas destas medidas foram postas em prática no momento, outras foram parcial ou posteriormente adotadas, com bastante sucesso. Enfim, caberia dar toda a atenção a esse 
momento ímpar, pois daqui se vê que muitas ideias novas e ousadas vieram, afinal, a ser adotadas mais cedo ou mais tarde e acabaram por determinar os rumos tomados pela produção de açúcar brasileira.

\section{Referências bibliográficas}

A LAVOURA. Boletim da Sociedade Nacional da Agricultura, 1908 a 1911.

ALMEIDA, Miguel Calmon Du Pin e. 1913. Factos econômicos. Rio de Janeiro: Livraria Francisco Alves.

BRASIL, 1906. Relatório apresentado ao Presidente da República dos Estados Unidos do Brasil pelo Ministro do Estado dos Negócios da Indústria, Viação e Obras Públicas Lauro Severino Muller, no ano de 1903, 18º da República. Rio de Janeiro: Imprensa Nacional, 1906.

CANABRAVA, Alice. A grande lavoura in: HOLANDA, Sérgio Buarque de (org) História Geral da Civilização Brasileira, volume seis, Rio de Janeiro: Bertrand Brasil, 1997.

EISENBERG, Peter Lous. A mentalidade dos fazendeiros no Congresso agrícola de 1878 In: LAPA, J. R. do A. Modos de produção e Realidade Brasileira. Petrópolis: Vozes, 1980.

GNACCARINI, J.C. A. A economia do açúcar: processo de trabalho e processo de acumulação In: FAUSTO, Boris. (org) História Geral da Civilização Brasileira, volume oito, Rio de Janeiro: Bertrand Brasil, 1997.

GUYOT, Ives. The Sugar Question in 1901. London: Hugh Press, 1991.

IAA. Brasil/ Açúcar (coleção canavieira nº 8). Rio de Janeiro: IAA, 1972.

MENDONÇA, Sonia Regina. O ruralismo brasileiro (1888 - 1931). São Paulo: Hucitec, 1997.

RIO DE JANEIRO.Mensagem apresentada à Assembleia Legislativa pelo Presidente do Estado do Rio de Janeiro General Quintino Bocayuva em 15 de julho de 1902. Rio de Janeiro, Typ. do Jornal do Comércio, 1902.

SAWYER, Frederic H. Relatório apresentado à Sociedade Paulista de Agricultura, Comércio e Indústria. São Paulo: Typ. De Carlos Gerke, 1905.

SOCIEDADE Auxiliadora da Agricultura de Pernambuco. 1879. Trabalhos do Congresso Agrícola do Recife em outubro de 1878. Recife: Tipografia de Manoel Figueroa de Faria \& Filhos. 
SOCIEDADE Nacional da Agricultura. 1907. Anais do Congresso Nacional de Agricultura instalado a 20 de setembro de 1901 no Rio de Janeiro. Rio de Janeiro: Imprensa Nacional.

\section{Notas}

${ }^{1}$ A Sociedade Auxiliadora da Agricultura de Pernambuco foi criada em 1872 e teve um importante papel na cobrança de políticas de auxílio à indústria açucareira, não só durante o Império, mas também na Primeira República.

${ }^{2}$ As cooperativas rurais, espontaneamente organizadas por pequenos produtores, tiveram seu apogeu na Europa entre 1890-1910. Nesse momento, foram uma forma de neutralizar a pressão social do período. Mendonça, 1997.

${ }^{3}$ Importa destacar que a situação de quase sobrevida experimentada pela Sociedade Auxiliadora da Indústria Nacional impôs ao País a realidade de contar com associações agrícolas somente no âmbito regional, como a Sociedade Campista de Agricultura (1834), a Sociedade Auxiliadora da Agricultura de Pernambuco (1870), dentre outras.

${ }^{4}$ Francisco de Paula Leite e Oiticica era advogado, político, deputado e senador por Alagoas, filho do médico e senhor de engenho Manuel Rodrigues Leite e Oiticica.

${ }^{5}$ Estácio Coimbra foi advogado, político e assumiu diversos cargos, dentre eles, deputado, senador, vicepresidente, governador de Pernambuco e ministro da Agricultura. Ademais, era senhor de engenho, casado com Joana de Castelo Branco Coimbra, membro da família proprietária do engenho Morim, mais tarde, Usina Central de Barreiros.

${ }^{6} \mathrm{O}$ parecer foi defendido por Estácio Coimbra, Matoso Câmara, Jacy Monteiro e Emmanuel Couret.

${ }^{7}$ Quanto às tarifas de exportação, ainda que pelo texto constitucional coubesse apenas ao governo central a atribuição de legislar sobre o assunto, as autoridades provinciais e até as municipais também o faziam. $\mathrm{O}$ Congresso Agrícola do Recife considerou "pesados, inconvenientes, injustos e inconstitucionais" os impostos que oneravam os produtores da grande lavoura sob a forma de direitos gerais e provinciais. Contudo, é de considerar que as autoridades não tinham alternativa, pois haviam fracassado as tentativas para a criação do imposto territorial, e a produção do países estava concentrada no gênero da grande lavoura, os quais, pela incidência dos impostos, deviam contribuir para quase toda a totalidade da receita em todas as esferas da administração. Desde que a lei de 1835 atribuiu às províncias uma parte dos direitos de exportação, tornava-se muito difícil extingui-los, ainda que, gradualmente, adotassem as províncias a estratégia de aumentar esses impostos todas as vezes que a assembleia geral aprovava sua redução. Tal prática reconhecia-se como ilegal, mas possivelmente se mantinha por razões políticas. Canabrava, 1997.

${ }^{8} \mathrm{Um}$ dos principais objetos da Inglaterra em estabelecer o acordo de Bruxelas era rivalizar com a política econômica açucareira norte-americana. Nesse período, os Estados Unidos já haviam estabelecido tarifas preferenciais e de acordos bilaterais de comércio, como os que vinham estabelecendo no caso do açúcar com alguns países recém-libertos do colonialismo europeu, com alguns países latino-americanos de sua área de influência, e mesmo com nações europeias industrialmente atrasadas: Espanha, Cuba e Filipinas, México, Peru e Argentina. A Inglaterra buscava, desse modo, enfrentar o fechamento do mercado norte-americano e a inclusão nele de outras áreas do comércio mundial. Gnaccarini, 1997, p. 317.

${ }^{9}$ Como aponta Gnaccarini (1997) "Ao propor em 1900, agora com mais sucesso, as medidas antiprotecionistas adotadas em boa medida pelo Convênio de Bruxelas, pelas quais vinha lutando desde 1865, o interesse da Inglaterra no controle mundial da produção de açúcar era uma dedução lógica do liberalismo econômico inglês. A supremacia inglesa no comércio mundial dependia de que a divisão internacional do trabalho não fosse submetida a desequilíbrios muito profundos. $O$ crescimento agrícola europeu se concorresse efetivamente com a produção colonial, poderia ser um dos fatores desse desequilíbrio. Isto era especialmente certo se a produção metropolitana se expandisse à custa de proteções antilivre-cambistas, e fosse acompanhada de superprodução de alimentos e matérias-primas de origem agrícola".

${ }^{10}$ Essa teia de interesses divergentes manteria acirradas as discussões sobre a adesão à Convenção de Bruxelas até 1905, quando aconteceu a Conferência do Açúcar de Recife. A maioria dos participantes defendeu que o Governo determinasse, antes da adesão, se o Brasil concederia subvenções diretas ou indiretas, explicitando as tarifas que assegurariam acordos comerciais com os países europeus. Mormente por o País aderir à Convenção de Bruxelas por poucos anos, de 1906-1910, não ocorreu nenhum aumento significativo das exportações brasileiras, como previram seus defensores. IAA. 1972.

${ }^{11}$ Para que se possam avaliar os efeitos da crise de 1901 no mercado mundial de açúcar, ver Guyot (1901) 
Reclamos da lavoura: A definição do programa de prioridades da indústria sacarina no Primeiro Congresso Nacional de Agricultura

${ }^{12}$ Usineiro, presidente do estado de Pernambuco, presidente da Conferência Açucareira da Bahia, organizador Conferência Açucareira Recife. Ele seria descrito posteriormente na Revista Brasil Açucareiro como um adiantado senhor de engenho da época.

${ }^{13}$ Paulo Amorim Salgado descreve sua atuação quando presidente do estado de Pernambuco no melhoramento das variedades de cana pelo uso da flecha, como um exemplo a ser seguido.

Recebido em dezembro/2011.

Aprovado em agosto/2012. 